\title{
Income Distribution, Borrowing Constraints and Redistributive Policies*
}

\author{
Carlotta Berti Ceroni and Giorgio Bellettini \\ Dipartimento di Scienze Economiche \\ Università di Bologna
}

September 22, 1999

\begin{abstract}
This paper proposes an explanation for why universal suffrage has not implied larger rich-to-poor transfers of wealth. The main argument is that, in the presence of borrowing constraints, if current taxation finances (at least partially) policies that redistribute future income, the poor, who are more likely to be liquidity constrained, may form a coalition with the rich and vote for low redistribution. In this context, the effects of an increase in income inequality on the level of redistribution depend on whether the increase in inequality is concentrated among the poor or the middle class. In the former case, an increase in inequality tends to decrease redistribution, whereas, in the latter case, it tends to increase redistribution.
\end{abstract}

*We would like to thank seminar participants at University of Bologna and at the ASSET 1999 Annual Meeting in Tel Aviv for useful comments. All remaining errors are ours alone. 


\section{Introduction}

Given existing inequality in income and wealth distribution, a natural question arises as to why the relatively poor majority does not use its political power to engage in larger redistribution and expropriation of the rich. If all citizens have the vote, and median wealth is less than the mean (as it is in reality) a majority of voters should prefer a tax rate of unity, fully redistributing all wealth to the mean.

In presence of distortionary costs of taxation, full expropriation is irrational. Yet, if the tax rate determined by majority voting is a decreasing function of the median/mean wealth or income ratio ${ }^{1}$, the question remains open of why extension of suffrage to the poorest segments of the population in the twentiethcentury did not bring about the feared large expropriation of the rich via the tax system in western democracies.

Several explanations have been put forward to account for the fact that universal suffrage has not implied larger rich-to-poor transfers of wealth. ${ }^{2}$ For instance, it has been suggested that political systems are biased against the poor, who are well known to participate less than the rich to political activity ${ }^{3}$. Also, if political competition concerns more than one issue (e.g. tax policy and religion) the equilibrium tax rate proposed by the party protecting the interests of the poor may decrease, as the salience of the non-economic issue increases. ${ }^{4}$ Finally, it has been pointed out that even people with below-average income will not support high tax rates if they expect to move upward the income ladder or if they recognize that there would be adverse dynamic effects of expropriating the rich. ${ }^{5}$

An alternative way to pose the question is by asking why redistribution does not appear to be higher in more unequal societies. Casual observation of crosscountry data shows that some of the most unequal countries of the world have relatively small welfare states. Benabou's [1] survey on inequality and growth summarizes recent empirical work in this area and concludes that inequality is

\footnotetext{
${ }^{1}$ See Meltzer and Richard [8] for a classic illustration of this argument.

${ }^{2}$ Putterman [12] reviews various explanations and tries to assess their degree of importance.

${ }^{3}$ For recent models developed along these lines, see Benabou [2] and Rodriguez [13].

${ }^{4} \mathrm{~T}$ his argument has been recently advanced by Roemer [14].

${ }^{5}$ See Benabou and $\mathrm{Ok}[3 \mid$ for a theoretical investigation of the former hypothesis. Perotti [10] includes the dynamic effects of current redistribution among the aspects evaluated by rational voters.
} 
not robustly associated with redistribution in cross-country data. In fact, the statistical association between inequality and various measures of redistribution is rarely significant and its sign, which is sometimes negative, heavily depends on the chosen specification. Rodriguez [13] obtains evidence of a negative association between inequality and redistribution by examining a panel of OECD countries in the period 1960-1990 and provides a theoretical model which is consistent with it, based on the unequal political power of the rich and the poor. Saint-Paul and Verdier [17] briefly discuss various theoretical arguments that can give rise to a negative effect of inequality on redistributive pressure. ${ }^{6}$ In particular, as shown in Saint-Paul [15], an increase in inequality which affects the bottom portion of the income distribution may imply an increase in the median/mean income ratio and therefore be associated with reduced taxation.

In this paper, we propose an alternative explanation for the non-expropriation of the rich in democracies, which provides useful insights on the relationship between inequality and redistribution and possible guidance in the specification of empirical tests of such relationship. The central idea of our work is the following. In a world with credit market imperfections, where agents vote over redistributive taxation, the median voter is not necessarily the agent (class) with median income. More specifically, if current taxation finances (at least partially) policies that redistribute future income, the poor segments of the population, who are more likely to be liquidity constrained, may vote for low redistribution, together with the rich. Therefore, instead of seeing all agents below the mean voting for high redistribution, we may expect the poor and the rich to form a coalition in favor of low levels of redistribution.

We formalize our main argument as follows. A two-period economy is inhabited by individuals who are heterogeneous with respect to their first-period labor productivity. In particular, we assume that there exist three income classes, the rich, the middle class and the poor. First-period income is homogeneous within classes and is below the mean for the two lowest income classes. Capital market imperfections exist such that, to some extent, agents may be prevented from borrowing as much as they should to carry out their optimal consumption plans. Fiscal policy is politically determined through majority voting in the first period.

\footnotetext{
${ }^{6}$ Peltzman [9] also presents a theoretical explanation of why the political pressure for redistribution should increase the more equal the distribution of income as well as empirical evidence consistent with it.
} 
Such policy involves current proportional distortionary income taxation which is used to finance either future lump-sum redistribution or current government expenditure, such as public investment in infrastructure and public expenditure on education, which increases the future productivity of labor.

In this context, the preferred tax rate will be decreasing with first-period income for agents who are not liquidity constrained, since the marginal cost of redistribution is higher for richer agents. Instead, the desired level of redistribution will increase with first-period income for agents who are borrowing constrained. The inability to borrow to finance current consumption mitigates the incentives to expropriate the rich for liquidity constrained agents, the more so the larger the difference between income and desired consumption in the first period.

This framework gives rise to different politico-economic equilibria, depending on the extent of borrowing constraints. When borrowing ceilings are high and no agent is liquidity constrained, the equilibrium tax rate will be the one preferred by the middle class. As the extent of borrowing constraints increases, a coalition of the poor and the rich is eventually formed, who favor a lower tax rate than the one preferred by the middle class. In other words, as borrowing ceilings fall, the identity of the median voter shifts from the middle class to the poor, who are borrowing constrained and are induced to decrease current taxation to increase current consumption. Since the efficient level of taxation is lower than the unconstrained optimal level of taxation of the middle class, higher degrees of borrowing constraints can be associated with higher levels of social welfare.

Our model has interesting implications about the effects of an increase in income inequality on the level of redistribution. These effects turn out to depend on whether the increase in inequality is concentrated among the poor or the middle class. In the former case, an increase in inequality tends to lower redistribution, whereas, in the latter case, it tends to increase redistribution.

In a recent paper, Saint-Paul [15] also obtains the result that more unequal societies can redistribute less if the increase in inequality is concentrated on the poorest. In his paper, the equilibrium tax rate decreases because the median income increases relative to the mean. In our set up, the result depends crucially on the change of identity of the median voter which is associated with higher inequality.

The plan of the paper is as follows. Section 2 describes the basic features of the model. In section 3 , the politico-economic equilibrium is determined. Section 
4 studies the relationship between inequality and redistribution and section 5 concludes.

\section{The model}

We will consider a two-period small open economy where agents are indexed by their first period endowment of human capital $e_{1}^{i}$. They belong to three income classes (poor, middle class and rich) denoted by $e_{1}^{1}<e_{1}^{2}<e_{1}^{3}$. The fraction of people in each class is given by $\mu^{i}$ with $0<\mu^{i}<.5$ and $\sum_{i=1}^{3} \mu^{i}=1$. We will assume that $e_{1}^{2}<E_{1}$ and $e_{1}^{3}>E_{1}$ where $E_{1}=\sum_{i=1}^{3} \mu^{i} e_{1}^{i}$.

In their first period of life, agents allocate their income between consumption and saving. The rate of return on savings is exogenous and equal to $r$. We assume that in the first period agents cannot borrow more than $\psi-1$ times their income to finance current consumption. The parameter $\psi \geq 1$ represents the degree of capital markets imperfection. When $\psi=1$, agents cannot borrow at all; when $\psi \rightarrow \infty$, there are no imperfections.

Individual income in the second period is given by $e_{2}^{i}=A G_{1}$ with $A \geq 1+$ r. $G_{1}$ represents public expenditure which increases the productivity of labor and is financed through proportional income taxation in the first period. In particular, we can interpret $G_{1}$ as public expenditure on education and on-thejob-training or as public investment in infrastructure. ${ }^{7}$ We assume that there are convex costs of collecting taxes, so that if $\tau$ is the tax rate, the actual revenue is $\left(\tau-\tau^{2}\right) E_{1}$. Balanced budget implies that $G_{1}=\left(\tau-\tau^{2}\right) E_{1}$. The level of taxation is determined in the first period through majority voting. The tax rate which cannot lose under majority rule will be the equilibrium tax rate.

Preferences are represented by the following intertemporal utility function:

$$
U^{i}=\log c_{1}^{i}+\beta \log c_{2}^{i}
$$

where $\beta \in(0,1)$ denotes the intertemporal discount rate.

\footnotetext{
${ }^{7}$ In the former case, we can think of Jabor income in the second period as deriving from a linear production function of the form $y_{2}^{i}=e_{2}^{i}$, where $e_{2}^{i}=A\left(e_{1}^{i}\right)^{\mu} G_{1}^{\nu}$. For simplicity, we set $\mu=0$ and $\nu=1$. In the latter case, the production function would be $y_{2}^{i}=A e_{2}^{i}\left(K_{2}^{G}\right)^{\nu}$ where $e_{2}^{i}=\left(e_{1}^{i}\right)^{\mu}$ and $K_{2}^{G}=G_{1}+(1-\delta) K_{1}^{G}$, with $\delta=1$. In this case $A=K_{1}^{G}=1$ in the first period.
} 


\section{The politico-economic equilibrium}

The politico-economic equilibrium is the solution of a two-stage maximization problem. First, given the level of taxation, agents choose consumption to maximize their utility function given by equation (2.1) subject to the usual budget constraints. Second, given the consumption functions obtained in the first stage, agents choose the level of taxation which maximizes their indirect utility function.

The maximization problem in the first stage can be written as follows:

$$
\begin{aligned}
\max _{c_{1}^{i}, c_{2}^{i}} U^{i} & =\log c_{1}^{i}+\beta \log c_{2}^{i} \\
\text { s.to } \quad c_{1}^{i} & =(1-\tau) e_{1}^{i}-s^{i} \\
c_{2}^{i} & =A G_{1}+s^{i}(1+r) \\
c_{1}^{i} & \leq \psi(1-\tau) e_{1}^{i}
\end{aligned}
$$

It is easy to verify that when the last constraint is not binding, the solution to the utility maximation problem yields:

$$
\begin{aligned}
& c_{1}^{i}=\frac{1}{1+\beta}\left[(1-\tau) e_{1}^{i}+e_{2}^{i} /(1+r)\right] \\
& c_{2}^{i}=\frac{\beta}{1+\beta}\left[(1+r)(1-\tau) e_{1}^{i}+e_{2}^{i}\right]
\end{aligned}
$$

In the second stage, agents choose the tax rate to maximize their indirect utility, obtained by substituting the optimal levels of consumption (3.1) in the utility function (2.1). Thus, the most preferred tax rate for agent $i$ is the solution to the following problem:

$$
\begin{aligned}
\tau^{i} & =\underset{\tau}{\arg \max }\left(\log c_{1}^{i}+\beta \log c_{2}^{i}\right) \\
\text { s.to } \quad c_{1}^{i} & =\frac{1}{1+\beta}\left[(1-\tau) e_{1}^{i}+A\left(\tau-\tau^{2}\right) E_{1} /(1+r)\right] \\
c_{2}^{i} & =\frac{\beta}{1+\beta}\left[(1+r)(1-\tau) e_{1}^{i}+A\left(\tau-\tau^{2}\right) E_{1}\right]
\end{aligned}
$$

The first order condition of this problem is:

$$
-(1+r) e_{1}^{i}+\left(1-2 \tau^{i}\right) A E_{1}=0
$$


which yields:

$$
\tau^{i}=\frac{1}{2}-\frac{(1+r) e_{1}^{i}}{2 A E_{1}}
$$

where $\tau^{i}>0 \Leftrightarrow(1+r) e_{1}^{i}<A E_{1}$. A standard result in the literature on the political economy of redistribution holds here: the richer is an agent, the lower is her preferred tax rate.

Equation (3.3) represents the optimal tax rate for agent $i$ if and only if, given $\tau^{i}$, agent $i$ is not borrowing constrained. This requires that $c_{1}^{i} \leq \psi\left(1-\tau^{i}\right) e_{1}^{i}$. This condition can be written as follows:

$$
e_{1}^{i} \geq \frac{A E_{1}}{(1+r)[2 \psi(1+\beta)-1]}
$$

If this inequality is satisified for all three groups, the optimal tax rate for the middle class cannot lose under majority rule. Any tax rate lower than $\tau^{2}$ will be opposed by a coalition of groups 2 and 3 , whereas any tax rate higher than $\tau^{2}$ will be opposed by a coalition of groups 1 and 2 . Thus we can write the following:

Proposition 1. Assume condition (3.4) holds for $i=1,2,3$. Then, the equilibrium tax rate will be $\tau^{2}$ with $\frac{\partial \tau^{2}}{\partial e_{1}^{2}}<0$.

As we just discussed, the tax rate given by equation (3.3) is the optimal policy for agent $i$ if and only if, given this level of taxation, agent $i$ is not liquidity constrained. In the remaining of the paper, we will assume that the unconstrained preferred tax rate of the rich is $\tau^{3}=0$. This requires that $e_{1}^{3}>\frac{A E_{1}}{(1+r)}$. Moreover, we will assume that $e_{1}^{i}<\frac{A E_{1}}{(1+r) \mid 1+2 \beta]}$ for $i=1,2$. This implies that, when the extent of liquidity constraints is sufficiently high, the borrowing constraint will be binding for the poor and the middle class. In other words, there exists $\psi^{i} \equiv$ $\frac{A E_{1}+(1+r) e_{1}^{i}}{2(1+\beta)(1+r) e_{1}^{i}}>1$ such that if $\psi<\psi^{i}$ agent $i$ will be liquidity constrained (notice that $\psi^{1}>\psi^{2}$ ). If this is the case, agent $i$ chooses her preferred tax rate by solving the following problem:

$$
\begin{gathered}
\tau^{i c}=\underset{\tau}{\arg \max }\left(\log c_{1}^{i}+\beta \log c_{2}^{i}\right) \\
\text { s.to } \quad c_{1}^{i}=\psi(1-\tau) e_{1}^{i} \\
c_{2}^{i}=(1+r)(1-\psi)(1-\tau) e_{1}^{i}+A\left(\tau-\tau^{2}\right) E_{1}
\end{gathered}
$$


The first order condition of this problem is given by:

$$
-1-\beta \frac{(1+r)(1-\psi) e_{1}^{i}-A E_{1}(1-2 \tau)}{(1+r)(1-\psi) e_{1}^{i}+A E_{1} \tau}=0
$$

which yields:

$$
\tau^{i c}=\frac{\beta A E_{1}+(1+\beta)(1+r)(\psi-1) e_{1}^{i}}{(1+2 \beta) A E_{1}}
$$

We can now prove the following preliminary results:

Proposition 2. (1) $\frac{\partial \tau^{i c}}{\partial \psi}>0$ (2) $\tau^{i c} \leq \tau^{i}$ (3) $\frac{\partial \tau^{i c}}{\partial e_{1}^{i}}>0$ (4) When $\psi=1, \tau^{i c}>0$.

Proof. (1) Obvious. (2) When $\psi=1, \tau^{i c}<\tau^{i} \Leftrightarrow A E_{1}>(1+2 \beta)(1+r) e_{1}^{i}$ which we already assumed to hold. Since $\frac{\partial \gamma^{i c}}{\partial \psi}>0$ and $\tau^{i c}=\tau^{i}$ when $\psi=\psi^{i}$, this concludes the proof. (3) Obvious. (4) Obvious.

Since redistribution takes place in the second period, the poor and the middle class may hit the borrowing ceiling at their unconstrained optimal tax rate. In this case, in order to relax the borrowing constraint, they will reduce their preferred level of taxation and increase the level of current consumption. The lower is the extent of borrowing constraints, the higher is the desired degree of expropriation by the low-income classes. Contrary to the standard theoretical result of a negative relationship between personal income and desired redistributive taxation, here the preferred tax rate increases with income.

Now, we can state the main result of this section:

Proposition 3. There exists a $\widehat{\psi} \in\left[\psi^{2}, \psi^{1}\right]$ such that (1) for $\psi \in[\widehat{\psi}, \infty]$ the equilibrium tax rate is $\tau^{2}(2)$ for $\psi \in[1, \widehat{\psi})$, the equilibrium tax rate is $\tau^{1 c}<\tau^{2}$.

Proof. First, we know that at $\psi^{2}, \tau^{1 c}<\tau^{2}$ (immediate: at $\psi=\psi^{2}, \tau^{2}=\tau^{2 c}>$ $\left.\tau^{1 c}\right)$. Next, we know that at $\psi^{1}, \tau^{1 c}=\tau^{1}>\tau^{2}$. Since $\partial \tau^{1 c} / \partial \psi>0$, there must exist a $\widehat{\psi} \in\left[\psi^{2}, \psi^{1}\right]$ such that $\tau^{1 c}(\widehat{\psi})=\tau^{2}$. Thus, for $\psi \in\left[\widehat{\psi}, \psi^{1}\right]$, preferred tax rates are such that $\tau^{3}<\tau^{2}<\tau^{1 c}$ and $\tau^{2}$ cannot lose under majority rule. For $\psi \in\left[\psi^{1}, \infty\right], \tau^{3}<\tau^{2}<\tau^{1}$ and $\tau^{2}$ cannot lose under majority rule. Thus for $\psi \in[\widehat{\psi}, \infty]$, the equilibrium tax rate is constant. For $\psi \in\left[\psi^{2}, \widehat{\psi}\right), \tau^{3}<\tau^{1 c}<$ $\tau^{2}$ and $\tau^{1 c}$ cannot lose under majority rule. For $\psi \in\left[1, \psi^{2}\right), \tau^{3}<\tau^{1 c}<\tau^{2 c}$ and $\tau^{1 c}$ cannot lose under majority rule. 
The intuition for this result can be grasped by looking at Figure 1. As this figure shows, the identity of the median voter depends on the extent of borrowing constraints. On the one hand, if the degree of borrowing constraints is low, that is $\psi>\widehat{\psi}$, the equilibrium tax rate is the optimal unconstrained tax rate for the middle class $\tau^{2}$ which lies between the preferred tax rates of the poor and the rich. On the other hand, when borrowing constraints are strong enough $(\psi<\widehat{\psi})$, the preferred tax rate of the poor (who are now liquidity constrained) is sufficiently low for them to become the median voters.

We conclude this section by discussing the relationship between our politicoeconomic equilibrium and the efficient tax rate, that is the one that maximizes the present discounted value of aggregate disposable income. This efficient tax rate is given by $\tau^{*}=\frac{1}{2}-\frac{(1+r)}{2 A}$. It is immediate to see that this relationship depends on the extent of borrowing constraints. In particular, we can show the following result:

Proposition 4. For $\psi>\widehat{\psi}$, the equilibrium tax rate is larger than the efficient level. For $\psi<\widehat{\psi}$, the equilibrium tax rate gets closer to the efficient level. As $\psi \rightarrow 1$, the equilibrium tax rate eventually becomes smaller than the efficient level, if and only if $A>(1+2 \beta)(1+r)$.

\section{Proof. Obvious.}

Notice that the relationship between the extent of borrowing constraints and welfare is positive, at least for $\psi \in\left[\psi^{*}, \widehat{\psi}\right]$ where $\psi^{*} \geq 1$ is implicitly defined by $\tau^{1 c}\left(\psi^{*}\right)=\tau^{*}$.

\section{Income inequality and redistributive policies}

So far, we have analyzed how the politico-economic equilibrium responds to changes in the extent of borrowing constraints. Now we want to investigate how the equilibrium fiscal policy changes when income distribution is altered. In particular, we will study the relationship between redistributive policies and income inequality. In order to do so, we will consider increases in the initial income of the rich $e_{1}^{3}$ coupled with decreases in the initial income of the poor $e_{1}^{1}$ or the middle class $e_{1}^{2}$. These modifications are assumed to leave the mean income $E_{1}$ unaffected. 
As we will immediately see, these two distinct ways of increasing income inequality have different implications on the equilibrium of the model. If we begin with the case where the income of the poor is reduced, we can prove the following result:

Proposition 5. Ceteris paribus, a meant-preserving reduction of $e_{1}^{1}$ will not increase the equilibrium tax rate.

Proof. Consider the graph in Fig. 2. Following the change in the distribution of income, $\psi^{1}$ and $\widehat{\psi}$ move to the right. There is now a larger subset of $\psi$ such that the poor is the median voter. This subset is given by $\left[\widehat{\psi}, \widehat{\psi}^{\prime}\right]$. Within this subset, $\tau^{1 c}<\tau^{2}$. Since, for $\psi<\widehat{\psi}$, the poor is still the median voter and $\tau^{1 c^{\prime}}<\tau^{1 c}$, this concludes the proof.

The above result differs from the conclusions of most recent theoretical studies, which highlight a positive relationship between inequality and redistribution. Instead, our last proposition shows that, if the increase in inequality is generated by a decrease in the income of the poor, the degree of redistribution will actually decrease (or remain constant). The intuition for this result can be illustrated by observation of Fig. 2. When the poor become poorer, their constrained optimal tax rate decreases, as implied by equation (3.6). At the same time, the extent of borrowing constraints for which the poor become liquidity constrained becomes lower (that is, $\psi^{1}$ increases). Therefore, the extent of borrowing constraints at which the constrained poor will choose a tax rate lower than $\tau^{2}$ (and thus become the median voter) will also be lower. Clearly, these changes imply that the equilibrium tax rate cannot be higher than the original one.

If we now perform the same experiment with respect to the initial income of the middle class, we obtain the following result:

Proposition 6. Ceteris paribus, a mean-preserving reduction of $e_{1}^{2}$ will not decrease the equilibrium tax rate.

Proof. Consider the graph in Fig. 3. Following the change in the distribution of income, $\psi^{2}$ and $\widehat{\psi}$ move to the right. There is now a larger subset of $\psi$ such that the poor is the median voter. This subset is given by $\left[\widehat{\psi}, \hat{\psi}^{\prime}\right]$. Within this subset, $\tau^{1 c}>\tau^{2}$. Moreover, for $\psi>\widehat{\psi}^{\prime}$, the middle class is still the median voter and $\tau^{2^{\prime}}>\tau^{2}$. This concludes the proof. 
As the last result makes clear, when the increase in income inequality is caused by a decrease in the income of the middle class, the effect on the amount of redistribution is the one which is usually predicted by the literature on the political economy of redistribution. In this case, the higher is the inequality, the higher (or constant) is the amount of redistribution. Consider Fig. 3. For $\psi<\hat{\psi}$, the poor is still the median voter and the equilibrium tax rate is unchanged. In the interval $\left[\widehat{\psi}, \widehat{\psi}^{\prime}\right]$, the identity of the median voter changes from the middle class to the poor and the equilibrium tax rate increases. Notice that the preferred tax rate of the middle class at lower income level is now higher than the preferred tax rate by the poor. Finally, for $\psi<\hat{\psi}^{\prime}$ the middle class is still the median voter and the level of redistribution increases.

\section{Conclusion}

In this paper we have shown that, by incorporating capital market imperfections in a political economy model of income redistribution, we can provide an explanation for why the majority of the population, whose income is below the mean, does not use its political influence to engage in large expropriation of the rich.

Some testable implications can be derived from our model. First, given the income distribution, increasing extents of liquidity constraints are associated with decreasing levels of redistribution. Second, as the income of the bottom class decreases, the level of redistribution tends to fall. Third, as the income of the middle class decreases, the level of redistribution tends to increase. The empirical investigation of these implications is the subject of a preliminary work( see Berti Ceroni and Bellettini [4]). 


\section{References}

[1] Benabou, R. (1996), "Inequality and Growth", NBER Working Paper no. 5658.

[2] Benabou, R. (1998), "Unequal Societies", forthcoming, American Economic Review.

[3] Benabou, R. and E.A. Ok (1998), "Social Mobility and the Demand for Redistribution: the POUM Hypothesis", CEPR Discussion Paper no. 1955.

[4] Berti Ceroni, C. and G. Bellettini (1999), "Income Distribution, Borrowing Constraints and Redistributive Policies: an Empirical Investigation", mimeo.

[5] De Gregorio, J. (1996), "Borrowing Constraints, Human Capital Accumulation and Growth", Journal of Monetary Economics, 37, 49-71.

[6] Jappelli, T. and M. Pagano, (1994), "Saving, Growth and Liquidity Constraints", Quarterly Journal of Economics, 109, 83-109.

[7] Lee, W. and J.E. Roemer (1998), "Income Distribution, Redistributive Policies and Economic Growth", Journal of Economic Growth, 3, 217-240.

[8] Meltzer, A. H. and S. F. Richard, (1981), "A Rational Theory of the Size of Government", Journal of Political Economy, 89, 914-927.

[9] Peltzman, S., (1980), "The Growth of Government", Journal of Law and Economics, 23, 209-288.

[10] Perotti, R., (1993), "Political Equilibrium, Income Distribution and Growth", Review of Economic Studies, 60, 755-776.

[11] Perotti, R., (1996), "Growth, Income Distribution and Democracy: What the Data Say", Journal of Economic Growth, 1, 149-187.

[12] Putterman, L. (1997), "Why Have the Rabble Not Redistributed Wealth? On the Stability of Democracy and Unequal Property," in Roemer, J.E. (Ed.), Property Relations, Incentives, and Welfare. London: Macmillan.

[13] Rodriguez, F. (1998), "Inequality, Redistribution and Rent-Seeking", Univerisity of Maryland, mimeo. 
[14] Roemer, J.E. (1998), "Why the Poor Do Not Expropriate the Rich: an Old Argument in New Garb", Journal of Public Economics, 70, 399-424.

[15] Saint-Paul, G., (1998), "The Dynamics of Exclusion and Fiscal Conservatism", mimeo.

[16] Saint-Paul, G. and T. Verdier (1993), "Education, Democracy and Growth," Journal of Development Economics, 42, 399-407.

[17] Saint-Paul, G. and T. Verdier (1996), "Inequality, Redistribution and Growth: a Challenge to the Conventional Political Economy Approach," European Economic Review, 40, 719-728. 